\title{
Does 'African mathematics' facilitate access to mathematics? Towards an ongoing critical analysis of ethnomathematics in a South African context ${ }^{1}$
}

\author{
Kai Horsthemke and Marc Schäfer \\ University of the Witwatersrand and Rhodes University \\ Email: Kai.Horsthemke@wits.ac.za and M.Schafer@ru.ac.za
}

\begin{abstract}
Mosibudi Mangena, the Minister of Science and Technology, said in an address to the Annual Congress of the South African Mathematical Society at the University of the Potchefstroom, November 2, 2004: "There is one thing we need to address before anything else. We need to increase the number of young people, particularly blacks and women, who are able to successfully complete the first course in Mathematics at our universities." How is this to be achieved? A popular trend involves a call for the introduction and incorporation of so-called ethnomathematics, and more particularly 'African mathematics', into secondary and tertiary curricula. Although acknowledging the obvious benefits of socalled ethnomathematics, this paper critically analyses three aspects of ethnomathematics that have been neglected in past critiques. Our focus is not on the relationship as such between ethnomathematics and mathematics education. Our critique involves (1) epistemological and logical misgivings, (2) a new look at practices and skills, (3) concerns about embracing 'African mathematics' as valid and valuable - just because it is African. The first concern is about problems relating to the relativism and appeals to cultural specificity that characterise ethnomathematics, regarding mathematical knowledge and truth. The second set of considerations concern the idea that not all mathematical practices and skills are necessarily culturally or socially embedded. With regard to the validity and viability of 'African mathematics', our misgivings not only concern the superficial sense of 'belonging' embodied in the idea of a uniquely and distinctly African mathematics, and the threat of further or continuing marginalisation and derogation, but the implicitly (self-)demeaning nature of this approach. This paper serves as a reminder that a critical position in the deliberations of ethnomathematics needs to be sustained. It warns against the bandwagon syndrome in a society where political correctness has become a prominent imperative. This paper is framed by many unanswered questions in an attempt to inspire and sustain a critical discourse in the ethnomathematics movement.
\end{abstract}

\section{Background}

The vision underlying the policy thrusts of the South African education system is captured in the Preamble to the Constitution which aims to "heal the divisions of the past and establish a society based on democratic values, social justice and fundamental human rights", to "lay the foundations for a democratic and open society" and to "improve the quality of life of all citizens and free the potential of each person", in order to "build a united and democratic South Africa able to take its rightful place as a sovereign state in the family of nations" (Republic of South Africa, 1996). "Education and the curriculum", it is stated in the introduction to the Revised National Curriculum Statement Grades R-9 (Schools): Mathematics, have an important role to play in realising these aims. The curriculum aims to develop the full potential of each learner as a citizen of a democratic South Africa. (Department of Education, 2002: 1)

Yet, the "review of educational progress", after ten years of democracy in South Africa,

revealed that, counter to the vision of policy, inequalities had increased, exacerbated by the deepening of poverty and its impact on education ... There remained serious questions with regard to access to quality education. ... An educational debate on access via school fees [arose in public in 2004], raising old questions about class, access and race within a new frame of emerging elites and ongoing inequalities. ... [The] managerial discourse around 'quality' ... is characterised by inflexibility and a desire

\footnotetext{
${ }^{1}$ An abridged version of this paper was presented at the Third International Conference on Ethnomathematics, Auckland, New Zealand in February 2006.
} 
for control. It narrows the view of quality and affects democratic processes surrounding discussions and debates about quality. In retrospect, it seems that the attempt to improve the quality of education, to bring about equality and support democracy in a globalising, market-oriented society, has met with mixed results. Policies seem to have been idealised and are remote from contextual realities. Democracy in education appears to exist in name only and falls short in its actualisation. (Kenton Conference, 2005)

Our paper attempts to explore these tensions and some of the proposed solutions, with special attention to mathematics education in South Africa. In particular, it seeks to (re)visit some of the more critical issues surrounding the incorporation of so-called 'African mathematics' into the mathematics education curriculum of South Africa. This paper arises out of our concern about the apparent intellectual complacency with regard to the theoretical and philosophical underpinnings of ethnomathematics - there is (certainly in South Africa) a view that a critical interrogation of ethnomathematics is passé, indeed undesirable. This, in our view, is a problematic attitude. We argue that if what inspires ethnomathematics is to strengthen its position, this requires ongoing critical reflection on its very assumptions and underpinnings. In essence, we are committed to the notions of transcultural truth and knowledge, in mathematics as elsewhere. We are concerned about the fragmentation of knowledge, and we reject the idea of ownership of knowledge, along ethnic and indigenous divisions.

Like the idea of 'indigenous knowledge', ethnomathematics has, in many circles in South Africa, unfortunately become a bandwagon-type of concept that has been uncritically co-opted by politicians and policy-makers to further their own agendas, without any reference to its philosophical and theoretical underpinnings. It tends to be employed as a buzzword in simplistically justifying the polarisation of (mathematical) knowledge into ethnic/indigenous, and 'world'/ mainstream. Although we do not dispute that mathematical learning arises and takes place in diverse socio-cultural contexts of meaning-making, we - like many others - find the uncritical 'ethnification' of mathematical knowledge problematic.

\section{The South African context}

According to the Revised National Curriculum Statement Grades R-9 (Schools): Mathematics, after providing a definition of mathematics and an account of the Mathematics learning area,

Being mathematically literate enables persons to contribute to and participate with confidence in society. Access to Mathematics is, therefore, a human right in itself. (Department of Education, 2002)

Mosibudi Mangena, the Minister of Science and Technology, said in an address to the Annual Congress of the South African Mathematical Society at the University of the Potchefstroom, 2 November 2004:

There is one thing we need to address before anything else. We need to increase the number of young people, particularly blacks and women, who are able to successfully complete the first course in Mathematics at our universities. (Mangena, 2004)

How is this to be achieved? A popular trend involves a call for the (re)introduction and (re)incorporation of a 'culturally informed mathematics', so-called 'ethnomathematics', and more particularly 'African mathematics', into secondary and tertiary curricula (see Emeagwali, 2003; Zaslavsky, 1979 \& 1994).

After providing an account of the African origins of mathematics (Seepe, 2000: 125-128; see also Van Sertima, 1999: 314-316; both writers seem to vacillate between an account of the "African origins of mathematics" and that of the "origins of African mathematics"), Sipho Seepe defends the desirability for a "culturally informed mathematics", an ethnomathematics approach as part of the 'democratisation' of curricula (Seepe, 2000: 131-133). He also reports on the DST/ CSIR' ${ }^{2}$ collaborative national audit of indigenous (South African) technologies (Seepe, 2000: 133134) that "was followed immediately by the launch of the Indigenous Knowledge Systems (IKS) Programme", a "Programme [that] is seen as a critical component in the restructuring and democratisation of the South African science and technology system, which has hitherto remained Eurocentric" (Seepe, 2000: 133, 134). Seepe concludes:

The challenge facing (South) African scholars is to build on this initiative and

${ }^{2}$ These acronyms stand for Department of Science and Technology and Council for Science and Industrial Research, respectively. 


\section{Does 'African' mathematics facilitate access to mathematics? Towards an ongoing critical analysis of ethnomathematics in a South African context}

engage themselves in unravelling the mathematical and scientific basis of these technologies. In other words, the challenge is to locate and identify the scientific skills, knowledge and process embedded in the cultural practices of the African majority. Once these are identified, they can be used to restructure, redesign and reformulate the present curricula. A restructured curriculum should assist in the affirmation of the African child. Since it is in culture and language that learners find an intellectual home, the utilisation of indigenous technology and African knowledge systems might be the key to unlocking the door that has prevented the masses from accessing mathematics, science and engineering. (Seepe, 2000: 134; see also

Department of Education, 2001)

However laudable his intentions, Seepe, like many others, seems to have fallen into the trap of polarising the notion of mathematical knowledge into 'mainstream' (in his case "Eurocentric") and 'ethnic' (in his case "African"). The notion of Eurocentrism (with particular reference to mathematics) has unfortunately become a buzzword that is bandied about without much thought or insight.

- What is a 'Eurocentric' science and technology system or, for that matter, system of mathematics?

- What makes it a Eurocentric system?

- What makes it Eurocentric?

Furthermore, how exactly is "the utilisation of indigenous technology and African knowledge systems" supposed to unlock "the door that has prevented the masses from accessing mathematics, science and engineering"? Seepe leaves these, and other, questions unaddressed and provides no further detail. Finally, the question of the African origins of mathematics is moot and not very helpful, and we do not intend to engage with it.

Rather, our concern here resides with the issue of the origins of African mathematics, in the sense that we question the existence of a uniquely and distinctly African mathematics (just as much as we question a uniquely and distinctly European mathematics). We argue that the interpretations and applications of mathematical concepts may be distinctly African (or European), but that to claim a uniquely ethnic or cultural ownership of mathematics is misleading and merely reinforces fragmentation and marginalisation.

\section{'Ethnomathematics'}

What follows is a brief discussion of a recent illustration of ethnomathematics. According to Paulus Gerdes, in his Stieg Mellin-Olsen Memorial Lecture presented in Bergen, Norway, on 31 August 2005, ethnomathematics embodies forms of valuing that include, or are contained in, understanding, recognition, sources of inspiration, as well as (African) renaissance. Explaining its central concerns, he quoted Stieg Mellin-Olsen: "To this day it has not been questioned at all whose culture, or which intellectual material, should be the basis for mathematics education" (Stieg Mellin-Olsen, Proceedings of the Conference on Mathematics and Culture, Bergen, September 1995; quoted in Gerdes, 2005). Using a concrete example of the value and distinctness of ethnomathematics, Gerdes explained that the 'right angle' ('epopera') in Mozambican basket weaving is not $90^{\circ}$ but $60^{\circ}$ - that is, the only angle that permits continuous folding, weaving and stability within the woven structure.

The 'classic' form design of the soccer ball (hexagons and pentagons) first introduced in the 1970 World Cup in Mexico may have already been in use in Thailand and Cambodia for some 2000 years, as Gerdes claimed, but this indicates the transcultural value and validity of design involving mathematical insights, rather than unique and distinct knowledge. Gerdes' reference to 'knowledge', throughout, concerns 'practical' knowledge or skills - so, invoking "complicated", pre-practice "calculations" (say, by indigenous basket weavers) appears to be no more than another way of describing a process of learning from trial and error. What about Gerdes' "examples of exclusively oral transmission of pottery design patterns" (by practitioners who had not engaged in pottery for years, as a result of the displacement forces of modernisation)? Do these indicate complex, extra-practice 'calculations'? Hardly: they might, rather, be said to indicate postpractice recollection.

Moving on to Sona/Cokwe sand drawings, Gerdes explained that the chief values in these drawings are considered to be symmetry and monolinearity, exceptions to which, however, do exist: asymmetry and bilinearity. Again, this indicates skills and creativity, certainly. Yet, the ability of so-called 'innumerate' (or, to use Gerdes' term, "unmatherate") people to count and to work with numbers in a broadly abstract fashion does not amount to 'indigenous' mathematics - any 
more than knitting inventiveness and skills attest to mathematical prowess.

On one level, then, 'ethno-' and related mathematics are descriptions of mathematical practices or skills through a cultural lens. On another level (after all, Seepe and others refer to "skills, knowledge and process"), they embody an epistemological relativism and/or invoke a notion of the cultural specificity of truth. The pertinent concerns might be grouped under the headings that follow.

\section{Pedagogical/pragmatic}

There is a view, for example, that mathematics may (already) be imbued with ethnomathematics, and that this is now an empirical matter, an open empirical question (Adam, Alangui \& Barton, 2003). This view is frequently accompanied by (reference to) accounts of how ethnomathematics permeates conventional mathematics and school curricula (for example, Adam, 2004).

There is, however, scant evidence that ethnomathematics as a general concept actually works. Research suggests that ethnomathematics may be meaningful only in a very narrow and localised context. For example, current research into the incorporation of Xhosa beadwork into a mathematics learning programme showed, inter alia, that only a very limited number of learners were able to identify with this practice and hence incorporate and assimilate it meaningfully into their learning experience. To many learners the practice of beadwork was foreign and old-fashioned, a practice that only their grandparents indulged in. This begs the question whether ethnomathematics is, indeed, a more appropriate way of doing mathematics. There appears to be little empirical evidence for giving an affirmative answer to this question. As a means for providing contextual, cultural and historical meaning to mathematics, ethnomathematics may be very useful, but to claim more than this is questionable.

At the recent $1^{\text {st }}$ African Regional Congress of ICMI held in Johannesburg in June 2005, a number of ethnomathematics researchers from Botswana presented their work. In the discussion that ensued after the presentations, it was interesting to note the observation that learners themselves frequently rejected the incorporation of 'African mathematics' (not to be confused with applied or practical mathematics), viewing it as irrelevant, exotic, backward, and culturally alienating. The assumption that the label 'ethno-' (or 'indigenous') will automatically be embraced by learners is clearly a dangerous one.
In the debate of product versus process, we warn against an over-emphasis on product (see, for example, Seepe, 2000: 134). Ethnic artefacts, baskets, pottery, sand drawings, and the like, arguably have a meaningful function as teaching and learning aids. Yet, it is unclear whether, as products, they occupy an equally significant function in a competitive, global 'knowledge economy' as, say, the products of general data handling and analysis.

\section{Political}

This concerns mainly issues of (lack of) access, exclusion and inclusion, and failure in learning mathematics (Mellin-Olsen 1987, chapter 5). According to Stieg Mellin-Olsen,

the failure in learning mathematics [is] a result of the pupil's lack or appreciation of the thinking-tools of the curriculum. ... [S] uch failure [is] political: some pupils are prevented from an important field of knowledge because of the design of the curriculum or the mechanisms of the examination system. (1987: 191)

In South Africa, unlike Mellin-Olsen's Norway, the situation has an additional dimension, that of past and present inequality, poor quality education and lack of democratic process "in a globalising, market-oriented society", where educational policies "seem to have been idealised and are remote from contextual realities" (Kenton Conference, 2005). After all, "[m]athematics is a product of investigation by different cultures $-\mathrm{a}$ purposeful activity in the context of social, political and economic goals and constraints", according to the Revised National Curriculum Statement Grades R-9 (Schools): Mathematics (Department of Education, 2002: 4). We need to recognise, however, that a familiar context in one class will be alien in another. The question is whether context-sensitivity requires, or at least renders desirable, a focus on 'indigenous mathematics'?

The politicisation of ethnomathematics may be interrogated on the basis of the following considerations:

- the bandwagon syndrome: indigenous knowledge systems, and ethnomathematics in particular, may be embraced for reasons of 'political correctness';

- the confusion of categories: mathematics (and the "interrelated knowledge and skills" that constitute it; see Department of Education, 2002: 4) is 


\section{Does 'African' mathematics facilitate access to mathematics? Towards an ongoing critical analysis of ethnomathematics in a South African context}

a science, and its laws, principles, functions and axioms have little, if anything, to do with issues of social justice.

\section{Philosophical/epistemological}

This concerns the philosophical assumptions behind the invocation of ethno-, indigenous or a uniquely and distinctly African mathematics.

Does the idea of ethnophilosophy (and, in particular, African philosophy of education) make any sense? There is at least a strong presumption against the plausibility of any such idea that, characteristically, tends to equate 'philosophy' with 'world view' rather than with 'critical [thinking] activity'. The problem with a purportedly uniquely and distinctly African philosophy is that either what is so presented is not obviously 'philosophy' in any profound or informative sense (since everyone would be a 'philosopher' on this understanding of the term) or it is not distinctly and uniquely African (see Horsthemke \& Enslin, 2005).

Where is ethnomathematics/'African mathemattics' vis-à-vis mainstream mathematics? How is it rationalised? Does the concept in question refer to practices and skills, or to bodies of theoretical/ factual/propositional knowledge? What about the possibility and desirability of a movement called 'gynomathematics' or, indeed - and ideally even joining forces with the former - 'Afrogynomathematics'? (What about the mathematics of insomniac Egyptian pyramid builders? This tongue-in-cheek question simply illustrates a concern about the fragmentation of mathematics.)

Are all mathematical practices equally valuable and/or valid? How, then, would one distinguish between good and bad mathematical reasoning?

Are mathematical skills essentially/characteristically embedded in culture and society? A possible response is that some skills - like basic numeracy skills - are universal, that is, translocal or transcultural. Additionally, there are obvious problems with relativism relating to knowledge and truth. Are there different, alternative bodies of mathematical knowledge in the theoretical/factual/ propositional sense, different deductive logics? (Ramagupta's mathematics was not 'Indian mathematics', but mathematics per se.)

\section{Some doubts about the notion of 'African' mathematics, in particular}

Realistically, when ethnomathematicians and indigenous knowledge apologists speak of the cultural specificity of mathematics, they are actually referring to traditions relating either to practices or to beliefs. We argue that ethnomathematics is, at best, a rhetorical tool for establishing relevance and promoting sensitivity to cultural differences - but neither a viable pedagogical nor epistemological construct.

We contribute to past and extant critiques of ethnomathematics (like Vithal \& Skovsmose, 1997; Rowlands \& Carson, 2002; Rowlands \& Carson, 2004) in that our critical focus is not on the relationship as such between ethnomathematics and mathematics education. Our critique of, and concern about, ethnomathematics emanates

1. from an epistemological and logical perspective,

2. on the basis of a new look at practices and skills,

3. from concerns about embracing 'African mathematics' as valid and valuable - just because (or on the mere grounds that) it is African.

The first concern is about problems relating to the relativism and appeals to cultural specificity that arguably characterise ethnomathematics, regarding mathematical knowledge and truth. The second set of considerations concern the idea that not all mathematical practices and skills are culturally or socially embedded. With regard to the validity and viability of 'African mathematics', our misgivings not only concern the superficial sense of 'belonging' embodied in the idea of a uniquely and distinctly African mathematics, and the threat of further or continuing marginalisation and derogation (vide 'African time'), but the implicitly (self-)demeaning nature of this approach.

A counterargument, however, might be that by taking apparent 'ownership of math', the west (Europe) has achieved precisely what Africa is trying to do now. It could be argued, for example, that our academic discourse is distinctly western, if not Eurocentric: consider the dominance of the English language - the medium of our discourse. Because mathematics has become part of this discourse it has arguably become distinctly western. This western/Eurocentric ownership, the argument concludes, has not led to any selfmarginalisation of any kind. The response to this contention would be that, if the idea of mathematics is to have any sense at all, reference to 'western' - let alone 'Eurocentric' - mathematics, perhaps by way of contrast with 'African' and other so-called 'indigenous' mathematics, is misguided. If something constitutes mathematics (or mathematical procedure), that is, the science of 


\section{Kai Horsthemke and Marc Schäfer}

number, quantity and space either studied in its own right or applied to other disciplines like physics or engineering, the questions around ownership or dominance are simply inappropriate. They have to do with (legitimate) concerns about historical and political processes and events rather than with mathematics as such. In addition, like the reference to a 'Eurocentric' and 'African' mathematics, the sheer sweeping generalisation involved in attributing certain characteristics to 'Europe' is as disconcerting as it is questionable. What is the referent here? 'Europe' is an invented idea, not an object. Are pacifist traditions or the green movement in some way un-European? Needless to remark, there exist both petty and profound enmities between members of different European nations. Given a similar diversity and stark cultural, economic and political differences within Africa, even 'Afrocentrism' seems unviable, unless both were interpreted in some sense as inwardlooking to the exclusion of what is outside/ different (see Horsthemke \& Enslin, 2005: 69).

Regarding the first concern referred to above, what is wrong with relativism? Logically speaking, epistemological relativism and relativism about truth are coherently expressible only as a relative knowledge-claim or truth - which undermines the relativist enterprise as much as expressing it as a universally applicable knowledge-claim or truth. In the former instance, the problem would be one of self-marginalisation. In other words, nonrelativists would not be, and could not be expected to be, impressed by relativists' claims or pronouncements. In the latter case, the problem would be that of self-contradiction. In other words, relativists would thereby be committing themselves to at least one nonrelative knowledge-claim or truth. Empirically, too, embracing relativism has undesirable consequences. These become obvious when, for the sake of argument (and bearing in mind that this cannot coherently be done in any non-relative fashion), we assume that relativism is true. What would be some of these consequences? First, we could not judge that the beliefs and practices of other societies are epistemically and veritistically inferior to our own, in terms of their knowledge and truth functionality. We could not say that something is a false belief or a superstition, or that something is a laborious, time-wasting practice. (Consider judging the beliefs and practices of a flat-earth society.) Second, we could decide whether beliefs are true or false and practices are the correct or incorrect ones simply by consulting the standards of our society or epistemic community. Third, the idea of progress (mathematical, scientific and other) is called into doubt, as is the idea of 'reform'. We would not be able to say that a new paradigm constitutes an improvement on the older paradigm it has replaced. In view of these consequences, not even considering the paradoxicality of denying the objectivity and universality of knowledge and truth, it appears to make more sense to assert that there is considerably less disagreement than it seems and that social and ethnic groups share a considerable body of mathematical knowledge and practices.

\section{Some thoughts about truth and 'the social'}

First, 'consensus' versus 'truth' in mathematics: mathematical concepts like that of area (space within a bounded surface) are universal. Descriptions of that bounded surface (such as number of square units etc.), on the other hand, may well be cultural products and, as such, a matter of cultural or social consensus. Similarly, the Pythagorean theorem is a human construct; yet, the relationship described exists independently of human in(ter)vention. 'Knowledge' is clearly not the same as 'consensus'. The latter may well be the product of a dialogical relationship, and this is what Marcelo Borba seems to be suggesting: "The teacher/researcher has a particular ability and responsibility to help the students find the intersections between their realms of meaning and the teacher's" (Borba, 1990/1997: 269). However, knowledge clearly goes beyond consensus: there may be consensus about what is false, untrue, not the case.

Second, the debate about the nature and status of mathematical truth waged between those who support a 'discovery' approach and those who endorse an 'invention' model. Obviously, the concepts employed in mathematics are 'human' in origin, yet to what they refer and are applied goes beyond human presence, agency or 'invention'. That is, while the terms and symbols denoting mathematical phenomena are, in an important sense, not discovered, the events and complex relations to which they refer are, again in an important sense, not invented or socially constructed. They are objectively accessible, translocal or transcultural phenomena.

To pre-empt any misunderstandings: we do not wish to play down the effects of colonialism or of its modern heir, globalisation. Nor do we intend to denigrate Africa's contribution to 'world mathematics' (Seepe, 2000: 127). We agree with many of the basic concerns that underpin ethnomathematics and an indigenous knowledge 


\section{Does 'African' mathematics facilitate access to mathematics? Towards an ongoing critical analysis of ethnomathematics in a South African context}

systems' approach, like concerns about the arrogant and patronising attitudes of 'mainstream' ('malestream'?) mathematicians, scholars and researchers, as well as the demand for relevance, that mathematics education should be sensitive to cultural differences, and so on. We differ, however, in our contention that while it is correct that many mathematical practices and skills (African or other) are "culturally and socially embedded", some skills - like basic numeracy skills - are not. There is ample empirical evidence that numeracy is not developed in any manner that places a premium on cultural or social influences and context. In short, we contend that there is no such thing as a body of knowledge called 'ethnomathematics'. Consequently, we argue that the focus on 'African mathematics', whether for reasons of 'political correctness' or social justice, that is, as a means of redressing "inequality, poor quality education and a loss of democratic process" (Kenton Conference, 2005), is seriously and significantly misguided.

Just as mathematical beliefs and ideas may differ among or across cultures, the manifestation of mathematical practices and skills may so differ. However, the former amount to knowledge only if they are true and if they are adequately justified. Similarly, while they may differ in their manifestation, mathematical activities and practices like "representation and interpretation; estimation and calculation; reasoning and communication; problem-posing; problem-solving and investigation; and describing and analysing" (Department of Education, 2002: 4) are transcultural, in that "they appear to be carried out by every cultural group ever studied" (Bishop, 1988, in Borba, 1990/1997: 266). It follows that the term 'indigenous' has, at best, limited applicability. A similar point could be made about the prefix 'ethno'. If ethnomathematics constitutes knowledge in the propositional or factual sense, then it is unclear what purpose the prefix is meant to serve - other than artificially severing ethnomathematics from mathematics as such. If it constitutes activities or practices, then - while their actual manifestations may differ among or across cultural or ethnic groups - the fact that these are carried out by all cultural or ethnic groups renders them universal. It follows that the term ethnomathematics encompasses, at the very most, the different ways in which mathematical activities and practices manifest themselves. These activities and practices need not be treated as anthropological curiosities but can enrich the teaching and learning of mathematics as such, as well as mathematical research.

\section{Concluding comments}

There appears to be a perception amongst proponents of ethnomathematics and of indigenous knowledge systems that discourse within the movement is now largely a matter of descriptive, empirical investigation (see, for example, Adam, Alangui \& Barton, 2003 and Adam, 2004). We have argued, against this perception, that critical and rigorous self-reflection and analysis of all its assumptions is crucial if ethnomathematics is to contribute meaningfully to curriculum development and implementation, in (South) Africa as elsewhere. After all, despite disagreement, there appears to be a shared, implicit assumption that even the most difficult and theoretical mathematical problems are amenable to discussion and argument. Moreover, there seems to be basic agreement on some transcultural standard of correct and incorrect reasoning in mathematics, as in other areas of intellectual life.

\section{References}

Adam, S. (2004). Ethnomathematical ideas in the curriculum. Mathematics Education Research Journal, 16(2), 49-62.

Adam, S., Alangui, W. \& Barton, B. (2003). A comment on: Rowlands and Carson 'Where would formal, academic mathematics stand in a curriculum informed by ethnomathematics? A critical review'. Educational Studies in Mathematics, 52, 327-335.

Borba, M.C. (1990). Ethnomathematics and education. For the Learning of Mathematics 10(1), 39-43. Reprinted in A.B. Powell \& M. Frankenstein (Eds.) (1997). Ethnomathematics: Challenging Eurocentrism in mathematics education (pp 261-272). New York, SUNY Press.

Department of Education. (2001). National strategy for mathematics, science and technology education. Pretoria: Government Printer.

Department of Education. (2002). Revised National Curriculum Statement Grades R-9 (Schools): Mathematics. Retrieved April 8, 2005, from http://www.education.gov.za/ content/documents/559.pdf

Emeagwali, G.T. (2003). African Indigenous Knowledge Systems (AIK): Implications for the Curriculum. In T. Falola (Ed.). Ghana in Africa and the World: Essays in Honor of Adu 


\section{Kai Horsthemke and Marc Schäfer}

Boahen. Trenton, New Jersey: Africa World Press. Retrieved April 8, 2005, from http://www.africahistory.net/AIK.htm

Gerdes, P. (2005). Forms of valuing embedded knowledge and creativity of so-called 'illiterate', 'unmatherate' people like 'indigenous' artisans. Stieg Mellin-Olsen Memorial Lecture, Scandic Hotel, Bergen, Norway, August 31, 2005.

Horsthemke, K. \& Enslin, P. (2005). Is there a distinctly and uniquely African philosophy of education? In Y. Waghid, B. Van Wyk, F. Adams \& I. November (Eds.). African(a) philosophy of education: Reconstructions and deconstructions ( $\mathrm{pp}$ 54-75). Stellenbosch: Stellenbosch University Department of Education Policy Studies.

Kenton Conference. (2005). (In)equality, democracy, and quality. Retrieved April 8, 2005, from http://www2.ru.ac.za/academic/depart ments/education resources/conference/About/i ndex.php

Mangena, M. (2004). Address to the Annual Congress of the South African Mathematical Society at the University of Potchefstroom. Retrieved April 8, 2005, from http://www.dst. gov.za/news/speeches/minister/mathematical_s ociety.htm

Mellin-Olsen, S. (1987). The politics of mathematics education. Dordrecht: D. Reidel.

Republic of South Africa. (1996). The Constitution. Pretoria: Government Printer.
Rowlands, S. \& Carson, R. (2002). Where would formal, academic mathematics stand in a curriculum informed by ethnomathematics? A critical review. Educational Studies in Mathematics, 50, 79-102.

Rowlands, S. \& Carson, R. (2004). A comment on Adam, Alangui, and Barton's "A comment on: Rowlands and Carson 'Where would formal, academic mathematics stand in a curriculum informed by ethnomathematics? A critical review". Educational Studies in Mathematics, 56(2-3), 329-342.

Seepe, S. (2000). Africanization of knowledge: Exploring mathematical and scientific knowledge embedded in African cultural practices. In P. Higgs, N.C.G. Vakalisa, T.V. Mda \& N.T. Assie-Lumumba (Eds.). African voices in education (pp 118-138). Lansdowne: Juta.

Van Sertima, I. (1999). The lost science of Africa: An overview. In M.W. Makgoba (Ed.). African Renaissance - The new struggle. Cape Town: Mafube Publishing.

Vithal, R. \& Skovsmose, O. (1997). The end of innocence: A critique of 'ethnomathematics'. Educational Studies in Mathematics, 34, 131157.

Zaslavsky, C. (1979). Africa counts: Number and pattern in African culture. Westport, Conn.: Lawrence Hill \& Company.

Zaslavsky, C. (1994). 'Africa counts' and ethnomathematics. For the Learning of Mathematics, 14(2), 3-8.

"It is truly difficult to make a democracy...

It is not what I say that says I am a democrat, that I am not racist or machista, but what I do." 